\title{
Metodologias ativas no ensino em ciências da saúde na visão dos estudantes de graduação
}

\author{
Glebson Moura Silva* \\ Maria Inez Oliveira Araujo** \\ Shirley Verônica Melo Almeida Lima*** \\ Renata Ramos Menezes**** \\ Thais Santos de Matos ${ }^{* * * *}$
}

\begin{abstract}
Resumo
O estudo investigou a visão dos estudantes de graduação em saúde sobre a aplicabilidade de metodologias ativas de ensino num Campus Universitário do Estado de Sergipe. No atual contexto, um dos importantes fatores revelados foi o déficit de conhecimento frente aos princípios da proposta pedagógica, uma vez que as metodologias ativas adotadas se apresentaram como facilitadoras do ensino e da aprendizagem através da participação dos sujeitos envolvidos, porém contraditoriamente houve barreiras que a limitaram, comprometendo encadeamentos importantes ao processo formativo. Espera-se que este saber aqui desvelado venha a contribuir com possíveis mudanças na formação do profissional de saúde.

Palavras-chave: Educação; Ensino; Saúde.
\end{abstract}

\section{Active methodologies of teaching in health sciences in the view of undergraduate students}

\begin{abstract}
The study investigated the vision of undergraduate health students around the applicability of active methodologies of teaching in a University Campus of the State of Sergipe. In the current context, one of the important factors revealed was the lack of knowledge regarding the principles of the pedagogical proposal, once the active methodologies adopted were presented as facilitators of teaching and learning through the participation of the subjects involved, but contradictorily there were barriers that limit it, jeopardizing important chaining to the educational process. It is hoped that this knowledge unveiled will contribute to possible changes in the training of the health professional.

Keywords: Education; Teaching; Health.
\end{abstract}

\section{Introdução}

Grandes questionamentos e inquietações dos teóricos e profissionais da área da educação superior versam sobre o papel das universidades na formação de profissionais para atuarem no mercado de trabalho com competência e autonomia. Com tanta informação disponível, despertar motivação para que o aluno saia do estado de espectador e se transforme num profissional competente, crítico e reflexivo, induz professores e profissionais da educação a pensar sobre como o conhecimento é construído.

Muitas vezes o professor universitário sabe o que ensinar, mas não detém a pedagogia de como ensinar. Considerando-se, ainda, que a graduação dura somente alguns anos, enquanto a atividade profissional pode permanecer por décadas e que os conhecimentos e competências vão se transformando velozmente, torna-se essencial pensar em metodologias para uma prática de educação que forme um profissional ativo e apto a aprender a aprender (MITRE et al., 2008).

*Endereço Eletrônico: glebsonmoura@yahoo.com.br

***Endereço Eletrônico: inezaraujo58@hotmail.com

***Endereço Eletrônico: shirleymelo.lima@gmail.com
Historicamente, a educação dos profissionais da saúde baseia-se no modelo biomédico, que enfatiza os aspectos biológicos, fragmenta o saber e fortalece a dicotomia entre teoria e prática (MITRE et al., 2008; SILVA; SÁ-CHAVES, 2008). Do mesmo modo, as metodologias de ensinoaprendizagem conhecidas como tradicionais são ainda amplamente utilizadas na formação dos profissionais da saúde. Nesses modelos de educação, destaca-se a transferência de conhecimentos pelo docente, a supervalorização da formação técnica e a dissociação entre o conhecimento teórico recebido passivamente pelo discente e o contexto social em que está inserido (FREIRE, 2004).

Destarte, o ensino na saúde esteve centrado em conteúdos, organizado de maneira compartimentada e isolada, com fragmentação dos indivíduos em especialidades da clínica, com dissociação entre o conhecimento das áreas básicas e o conhecimento das áreas clínicas, onde as oportunidades de aprendizagem se centravam no hospital universitário, e o sistema de avaliação era

\footnotetext{
*Endereço Eletrônico: renata.ramos.menezes@hotmail.com Endereço Eletrônico: thaislz@outlook.com
} 
cognitivo por acumulação de informação técnicocientífica padronizada, com incentivo a precoce especialização, e perpetuação de modelos de prática em saúde enquanto imutáveis (FEUERWERKER, 2003).

Neste contexto, as metodologias ativas surgiram como alternativa para se vencer a formação essencialmente biomédica, ao direcionar a sua adoção a partir do advento das diretrizes curriculares nacionais para os cursos de graduação em saúde. Nesta perspectiva, a Universidade em estudo tem em seu projeto pedagógico a meta de transpor o ensino da clínica e se aproximar da visão crítica e reflexiva, a fim de formar um profissional com capacidade de aproximar a prática Assistencial da Educacional (CYRINO; TORALLES-PEREIRA, 2004).

Existe uma infinidade de métodos ativos de Educação, todavia Bastos (2006) nos apresentou uma conceituação de Metodologias Ativas como processos interativos de conhecimento, análise, estudos, pesquisas e decisões individuais ou coletivas, com a finalidade de encontrar soluções para um problema. Nesse caminho, o professor atua como facilitador ou orientador para que o estudante faça pesquisas, reflita e decida o que fazer para atingir os objetivos estabelecidos. Segundo o autor, trata-se de um processo que oferece meios para que se possa desenvolver a capacidade de análise de situações com ênfase nas condições loco-regionais e apresentar soluções em consonância com o perfil psicossocial da comunidade na qual se está inserido.

Bastos (2006) e Berbel (2011) referem algumas possibilidades de metodologias ativas, a saber: estudo de caso, método de projetos, aprendizagem baseada em problemas, metodologia da problematização, aprendizagem baseada em equipes, aprendizagem por projetos, dentre outros. Porém, na realidade da Universidade pesquisada, quando se fala em metodologias ativas, está se referindo a apenas duas, que são: a aprendizagem baseada em problemas e metodologia da problematização.

A relevância deste estudo está sustentada na avaliação que pode ser feita do uso destas metodologias adotadas pela Universidade, que tem como meta a formação do profissional-cidadão, crítico e reflexivo para a área da saúde, ou seja, profissionais que aliem competência técnica, ética e humanística (BRASIL, 2001) com a concepção dos alunos inseridos neste contexto.

Nesta perspectiva, se teve como intenção identificar a visão dos estudantes de graduação em saúde sobre as metodologias ativas aplicadas no Campus Universitário, e, como consequência, respaldar o instrumento de coleta de dados com a devida validação para posteriores estudos.

\section{Metodologia}

O desenvolvimento histórico da formação em saúde sempre foi pautado, desde a sua gênese, na valorização dos aspectos biomédicos. Por isso, nas ponderações a respeito da formação dos profissionais de saúde, se observa o esforço em afirmar quão inadiável é ressignificar esta formação por meio de movimentos que envolvam propostas de mudanças relativas a alterações em processos, relações e conteúdos que podem ocorrer no plano da inovação de uma disciplina, da reforma curricular e da transformação do ensino e seus respectivos processos de aprendizagem. As incertezas e a transitoriedade dos conhecimentos que afetam a educação em saúde levam a mudanças de paradigmas e novas concepções de ensino.

Diante desta assertiva, convém investigar este fenômeno que segundo Richardson (1999) por ser uma investigação educativa pode acolher diferentes paradigmas, epistemologias, formas de conhecer e construir conhecimentos, pois investiga fenômenos educativos, e isto implica trabalhar com um objeto de estudo social - o humano, que não é medido ou mensurável.

Por isso, optou-se pela construção de um formulário que permitisse aos sujeitos, expor suas impressões e experiências, e, das subjetividades referidas analisar os processos metodológicos adotados na Universidade. Este foi iniciado por meio de percepções pessoais das adaptações e resistências frente ao uso de metodologias ativas aplicadas durante o trabalho na Universidade. Para identificálas foi buscado depoimentos de professores e alunos, selecionados por conveniência, de acordo com a proximidade, capacidade de expressão e disponibilidade de colaboração. Os depoimentos ajudaram na elaboração das questões que comporiam o formulário, pois permitiu identificar, explorar e hierarquizar os conhecimentos subjacentes ao desenvolvimento de ações e situações permeadas por metodologias ativas. Por meio desta estratégia foi estabelecido um conjunto de características essenciais à significação e à definição de conceitos a integrar a formulação dos itens destinados à avaliação das bases teórico-conceituais, concepções, percepções e atitudes dos sujeitos desta pesquisa. Para tanto, recorreu-se a um grupo de especialistas 
constituído por dois enfermeiros, dois biólogos, um farmacêutico, um fisioterapeuta e dois bolsistas de iniciação científica que trabalhavam com a temática e são alunos do Campus. O que resultou na primeira versão do formulário.

O instrumento elaborado foi ainda sujeito a uma cuidadosa avaliação feita em consenso pelos autores, o que fez surgir a segunda versão onde foram incorporadas outras questões associadas à formação em saúde. O formulário foi respondido por 33 estudantes estratificados ao longo dos anos e curso de formação em saúde: Enfermagem, Farmácia, Fisioterapia, Fonoaudiologia, Medicina, Nutrição, Odontologia e Terapia Ocupacional. Em sua estrutura foi dividido em dois blocos: 1) Questões voltadas para o perfil sociodemográfico dos estudantes; 2) Bases teóricoconceituais/conhecimentos e atitudes frente à aplicabilidade das metodologias ativas. Finalizou-se o formulário solicitando sugestões de melhoria do instrumento e temas a serem abordados dentro da problemática apontada.

As respostas foram tabuladas e interpretadas utilizando a estatística descritiva, seguida da interpretação do discurso escrito dos sujeitos da pesquisa. Estes foram informados sobre os objetivos da pesquisa, seus potenciais benefícios, ausência de danos, confidencialidade e a privacidade das informações e a não utilização delas em prejuízo das pessoas com a não identificação de nomes ou número de documentos. Por isso, foram usados códigos E1, E2, E3 e assim sucessivamente ao sinalizar para as falas dos estudantes que participaram da pesquisa. Todos os critérios éticos estabelecidos pelo Conselho Nacional de Saúde, Resolução 466/2012 (BRASIL, 2012), foram atendidos com aprovação pelo Comitê de Ética da Universidade, protocolado por meio da Plataforma Brasil, segundo parecer 1.021.823 de 10 de abril de 2015.

\section{Resultados}

Participaram do estudo 33 discentes estratificados por ano/ciclo e curso de graduação. Destes, 30 eram do sexo feminino e 3 do sexo masculino com faixa etária predominante de 18-24 anos; 32 referiram conhecer apenas o ensino tradicional e apenas 1 informou que já conhecia a aprendizagem baseada em problemas (ABP) antes da graduação.

Os estudantes foram questionados sobre as metodologias de ensino adotadas pela instituição, 30 deles responderam que elas facilitam a aprendizagem, justificando que há incentivo a uma dedicação maior para o estudo; desenvolve uma melhor autonomia, entusiasmo em aprender e visão crítica, referindo como positiva a 'pressão' que o aluno passa para buscar o conhecimento e fixação do conteúdo. Todavia, foram enfáticos ao discordar da obrigatoriedade do aluno em estudar por causa da avaliação diária; da objetividade dos assuntos que são propostos; da facilidade na discussão, pois muitos são tímidos e apresentam dificuldade de falar em público; das habilidades geradas para a resolução dos problemas, ficando apenas na esfera cognitiva; do envolvimento do conteúdo com a prática, muitas vezes divergentes. Eles fundamentaram seus argumentos no pouco tempo disponível para estudar e aprender muitos conteúdos - aqui foi notório o foco que estas pessoas deram ao conteúdo e as competências necessárias para triunfar no método.

Em relação à correlação das estratégias de ensino adotadas em aula com a integração/mobilização dos conteúdos com as demais atividades do curso, a maioria apontou que as atividades se relacionam e sempre veem a teoria seguida da prática; também tem a facilidade no trabalho em grupo e a associação de vários aspectos do mesmo conteúdo. Todavia tiveram o posicionamento crítico de referirem que: "facilita, mas poderia ser melhor"; "algumas atividades se inter-relacionam, o que facilita, outras, porém, atuam independentes" (E1); "não há uma correlação entre Tutorial, Habilidades e Prática de Ensino na Comunidade (PEC)" (E12) "por falta de organização" (E27). Parece contraditório, ao falarem que não há relação entre teoria e prática e depois apontarem que a prática vem logo depois da teoria, mas aqui eles associaram a apenas uma das atividades do currículo - PEC - enquanto na resposta anterior eles foram genéricos ao afirmar esta distância.

Questionou-se também sobre o reconhecimento da profissão nas atividades desenvolvidas, e foi justificada por: aproximação desde o início do curso das aulas práticas; integração do conteúdo; e experiência do professor. Algumas falas justificam tal percepção: "Porque na PEC percebe-se uma aproximação maior com os pacientes avaliando sua questão social" (E13); "As estratégias evidenciam as dificuldades inerentes à profissão, pois o sistema público de saúde também é deficitário e os professores nos alertam quanto à forma de agir diante desses déficits" (E31); "As correlações clínicas e visão da relação com o 
paciente" (E9). Ou seja, se percebe um contato precoce destes alunos com a comunidade e com os pacientes/usuários dos serviços de saúde, geralmente conseguidos por meio das aulas práticas na atividade de PEC, onde é desenvolvida nas unidades básicas de saúde. Alguns alunos também responderam negativamente em relação à questão, pois inferiram que "no primeiro ano (I Ciclo), não se observa muito, não há uma facilidade desta percepção, pelo contrário, existe uma dificuldade por conta da atuação passiva de alguns tutores (E21)"; "algumas disciplinas são difíceis e dificultadas pela ABP" (E16); "a grande dificuldade que ainda existe em relacionar os assuntos à prática clínica, o que acaba tendo muita teoria" (E7).

Quase todos os alunos referiram que as estratégias de ensino estimulam a sua participação nas discussões dos temas e o trabalho em equipe, pois é fomentada a interação entre os alunos, compartilhando conhecimento; outra questão é a forma de avaliação, onde o aluno é dependente da nota, que pode sofrer interferência da não participação; colaboração e entrosamento no grupo onde há sempre espaço para o diálogo, o aluno tornase ativo, possibilitando se sentir mais preparado e confiante em relação aos assuntos. Todavia sinalizam que "O método não funciona para pessoas tímidas" (E3); "Ainda há certa dificuldade de alguns professores entenderem a individualidade de cada aluno" (E11); "Ainda inibe pessoas que 'travam' quando são interrompidas em sua fala" (E32).

Estes alunos também apontam as metodologias ativas e os casos clínicos como importantes estratégias para a integração das atividades e a formação profissional. As "Metodologias ativas" porque abrangem a participação maior do aluno na sala de aula; maior criticidade, reflexão, contato precoce com pacientes, mais práticas médicas, visão humanística; o direcionamento do conteúdo; e a independência na construção do próprio conhecimento. Os "Casos clínicos" devido à realidade do profissional que é mostrada, pois integra diferentes assuntos aprendido em diferentes atividades - como a relação entre aspectos fisiológicos e a etiologia de um distúrbio com as manifestações, sinais e sintomas, dados de exames, e medicamentos em uso, levando em consideração diferentes aspectos.

Quanto às Diretrizes Curriculares dos cursos de saúde, os alunos demonstraram não conhecê-las em sua íntegra, nem mesmo seu direcionamento para a formação do profissional com um perfil generalista, crítico, reflexivo, e com competências para atuar nas diversas dimensões da ocupação humana, mas apontaram como estratégico o uso de metodologias ativas para o ensino com vistas a uma melhor atuação profissional.

Para o entendimento do aluno sobre metodologias ativas e atitudes voltadas ao processo de ensino-aprendizagem trouxeram respostas voltadas ao ativismo do aluno; o aluno como centro e responsável em sua aprendizagem; o estudo autodirigido; a aprendizagem horizontal e multidisciplinar; o professor é um facilitador, orientador, que pode ser questionado; o contato com a realidade e a vivência na comunidade; e a atuação profissional humanista e independente, visando novas possibilidades.

Seguem algumas respostas: "Entendo como um processo amplo onde a principal característica é $a$ inserção do aluno como agente principal $e$ responsável pela sua aprendizagem." (E3); "Proporciona ao aluno uma aprendizagem multidisciplinar e formação profissional humanizada." (E8); "É a metodologia onde o aluno se torna ativo na universidade e na comunidade." (E33); "É uma metodologia em que os alunos são vistos como principais responsáveis pela formação do conhecimento, mas que precisa de uma ótima estrutura $e$ de boa formação anterior para funcionar." (E13); "Forma de ensino-aprendizagem em que os alunos têm oportunidade de aprender de forma horizontal. Em que o professor é um orientador e o aluno é o autor de sua própria forma de aprender." (E23).

Quanto às atitudes foi vislumbrado que os alunos têm conhecimento do método e das atividades que são desenvolvidas na Universidade como grupo de estudo, monitoria, grupos de tutorial, habilidades e PEC, oficinas de trabalho, estágio extracurricular, disciplinas integrativas, transversais $\mathrm{e}$ interdisciplinares. Todavia, ficou notório que uma pequena minoria se vê como parte constituinte ao sucesso do método e/ou atua noutras atividades além do ensino, como bolsista ou monitor. Muitos justificados por meio do tempo que se dedicam ao estudo autodirigido que é o tempo destinado ao estudo de conteúdos voltados para a atividade de tutorial.

Por fim, sinalizam-se alguns anseios e desabafos: “As metodologias ativas não são adequadas à população em geral, pessoas tímidas, com base educacional fraca, com dinâmica tradicional tem muita dificuldade para adequar-se ao método. Talvez uma metodologia mista tivesse melhor aceitação e resposta que a ativa em si." 
(E20); "Será que o modo de avaliação empregado na instituição é algo que contribui na formação?" (E23); "As dificuldades que os estudantes do ciclo I passam para se adequar a essas novas metodologias é muito grande, raramente encontramos um meio que nos faça ter mais força de vontade de superar, o que acaba levando, em muitos casos, a desistência do aluno." (E31).

\section{Discussão}

O primeiro aspecto a se realçar foi uma característica predominante entre os estudantes - ter o primeiro contato com as metodologias ativas na graduação, ou seja, estes indivíduos desconhecem qualquer base teórica e/ou conceitual destas metodologias e se veem obrigados (expressão usada pela maioria) a se adaptar a um método que ainda não foram convencidos que seja o melhor. Este contexto de incertezas leva a pensar que esta mudança é contextual e envolve a forma com que o sujeito convive com sua aprendizagem, assim como fez lembrar Perrenoud (2001) quando apontou a relação entre mudanças escolares e sociais, enfatizando ser utópica aderir às propostas de reforma sem resistências. Assim, é trazida esta resistência representada pelo aluno ao questionar e não se adaptar às metodologias propostas.

Talvez isto aconteça, porque o desejo de mudança da escola para adaptá-la a contextos sociais, na maioria das vezes, não é partilhado pela escola e, se constitui em desejo frequentemente frágil, limitado a discursos (PERRENOUD, 2001). É pertinente esta citação, pois traz à tona a necessidade de corresponsabilização, participação e empoderamento dos estudantes nos processos de mudança. As imposições e obrigatoriedades geram resistências ou subversões que não estão restritas à população discente. E, assim, segue os pilares de um novo modelo de escola, de currículo e, principalmente, de trabalho docente orquestrado por diferentes metodologias e se colocam, em segundo plano, os demais problemas que o ensino enfrenta como problemas de acesso e permanência, que estão ligados a questões de investimentos, tanto na educação, quanto na geração de emprego e renda (PENIN; VIEIRA, 2002).

Por isso, talvez algumas queixas retratadas pelos alunos pudesse ser legítimas como "o pouco espaço físico e de acervo bibliográfico, a falta de recurso financeiro e material, a sobrecarga de conteúdo e a má divisão deste ao longo dos ciclos" (E11). Elas retratam questões estruturais, de acesso e investimento. Isso implica numa relação parcial do aluno com as atividades do curso, e não no êxito ao conciliar tempo com as ações de projetos. Talvez isso tenha sido dito porque o currículo da Universidade organiza-se por módulos ou eixos temáticos, e não por disciplinas, o que resulta em alterações gerais na organização e na gestão deste, além de alterações estruturais nos cursos. A sua operacionalização necessita de estrutura material mais complexa e em maior volume do que o habitual. Essas exigências fazem com que sua efetividade seja mais difícil e onerosa uma vez que se trabalha em pequenos grupos e com diversificados espaços de aprendizagem (FREITAS, 2005; BORGES et al., 2014).

Também se faz necessária "a capacitação de professores para as metodologias ativas" (E31), ela é apresentada como uma necessidade presente quando se propõe mudança no uso de metodologias de ensino, por grande parte dos autores estudados, uma vez que estas supõe um redirecionamento das estratégias de ensino e uma nova forma de lidar com o conhecimento. Tais fatos são condizentes com o estudo de Almeida e Batista (2013) quando apontaram a força da capacitação, orquestrada pela Universidade e de forma contínua, para o desempenho docente com as metodologias ativas. Com Albanese e Mitchell (1993) ao reconhecerem que, para que o processo de ensino por metodologia ativa ocorra de forma harmônica, o docente precisa estar sensível ao seu papel e deve ser submetido a uma formação cuidadosa e detalhada, a qual deverá ser necessariamente seguida de um acompanhamento atento e contínuo. Também com Quinlan (2003) ao afirmar que a Universidade deve favorecer a criação de espaços que promovam a interação entre os docentes que, habitualmente, estavam isolados em suas diferentes áreas de especialidades, nos moldes de ensino convencionais. A autora comentou que compreender como o docente aprende a partir do processo de ensinar ajuda os educadores na construção curricular a criar oportunidades de aprendizagem, tanto para os professores como para os estudantes.

O princípio é de um profissional autônomo, crítico e reflexivo, que possa dar continuidade às ações inovadoras no processo ensino-aprendizagem. Assim, os professores serão capazes de estimular o aluno, permitindo o exercício da pergunta e a imersão do mesmo em sua realidade. Ele deve assumir uma posição de facilitador nesse processo, para que revele experiências coerentes e importantes, despertando no aluno, um comportamento investigativo diante do mundo (BORGES et al., 2014). O que se pensa ser 
um fator limitante nos discursos dos alunos, pois a noção de autonomia referida está apenas associada ao estudo autodirigido (realizado fora da sala de aula). Este sujeito deve ser tratado enquanto ativo e independente, imerso na vida social e política, que não se limita apenas ao seu campo pessoal de ação e vivência, mas também envolve, em seu perfil, a construção de uma autonomia do pensar, e não apenas do ser (SERAFINI, 2012).

Nas metodologias ativas adotas, se supõe um ensino voltado ao diálogo, à liberdade e a uma busca constante do conhecimento participativo e transformador, em que o ser humano é entendido como sujeito de sua própria aprendizagem, e não como mero objeto passivo e heterônomo diante do saber. Devem ser levadas em conta a experiência e a forma de ver o mundo do educando para que esta aprendizagem seja efetiva. A educação, hoje, não se caracteriza por mero dever de transmitir informação, mas visa fomentar e resgatar as potencialidades individuais do sujeito aprendente, objetivando a construção de um conhecimento coletivo, onde a experiência de um se correlaciona com a vivência de outro (FREIRE, 2004). Ou seja, é uma autonomia entre seres humanos com o objetivo de aprender e apreender o mundo, sendo mais abrangente que autonomia de estudar sozinho, ler um livro, um artigo ou qualquer outro elemento, pois sobrepõe esta obrigatoriedade muitas vezes já referida pelo docente em sala de aula.

Faz-se necessário, então, construir e talvez reconstruir novos rumos para a educação autônoma e consciente, respaldando o aprendizado para a vida, procurando orientar o aluno para uma via de produção coletiva, mas desenvolvendo a autonomia em cada um. Autonomia de saber escolher para tomar decisões, ser capaz de criar, respeitando a ética em meio à coletividade. Autonomia que exerce papel essencial na concepção problematizadora, na qual o ato de aprender não é passivo, e nem o ato de ensinar se resume em depositar informações, mas um processo que acontece no contato do educando com o mundo vivido, o qual está em constante transformação (SERAFINI, 2012).

Isso também se reflete no processo avaliativo destes estudantes, aqui com destaque para a avaliação formativa. Para Haydt (1995), esta avaliação visa constatar se os alunos, de fato, estão atingindo os objetivos pretendidos, verificando a compatibilidade entre tais objetivos e os resultados efetivamente alcançados durante o desenvolvimento das atividades propostas. Ainda segundo a autora, esta forma de avaliação representa o principal meio através do qual o estudante passa a conhecer seus erros e acertos, encontrando, assim, maior estímulo para um estudo sistemático dos conteúdos.

Outro aspecto importante destacado, é o da orientação fornecida por este tipo de avaliação, tanto ao estudo do aluno como ao trabalho do professor, principalmente por meio de mecanismos de feedback. Estes mecanismos permitiriam, então, ao professor "detectar e identificar deficiências na forma de ensinar, possibilitando reformulações no seu trabalho didático, visando aperfeiçoá-lo" (HAYDT, 1995, p.17). Ou, ainda, na definição de Bloom, Hastings e Madaus (1975), a avaliação formativa visa informar ao professor e ao aluno sobre o rendimento da aprendizagem no decorrer das atividades escolares e a localização das deficiências na organização do ensino para possibilitar correção e recuperação.

Ainda assim, na Universidade esta avaliação também se processa no âmbito coletivo (grupo de alunos inseridos em sala por estratificação de ano e curso, sendo que no $1 .^{\circ}$ ano a estratificação serve para deixar o grupo heterogêneo, ou seja, todas as turmas possuem alunos de todos os oito cursos do campus). Neste ponto, um aluno referiu: "A dificuldade de entrosamento e cooperação no grupo" (E24) e acredita-se que este aspecto precisa ser considerado no processo, pois a cooperação para o trabalho em equipe, segundo Mitre et al. (2008), é uma das características fundamentais a serem desenvolvidas no perfil do estudante nesse tipo de metodologia. Segundo essa pesquisa, a atividade trabalhada com o propósito de ensinar deve ser valorizada por todos aqueles que dela participam, e também, é importante compreender que, esse processo de aprendizagem é dinâmico e reconstrutivo, envolvendo vários tipos de relações. O diálogo constitui uma estratégia norteadora nesse processo, em que permite que o docente avalie o desenvolvimento do discente de acordo com o relacionamento com o grupo e a sua comunicação (MELO; SANT'ANA, 2012).

Outros pontos que merecem atenção, e que foram destaques nas respostas dos alunos foram: "déficit de correlação entre as atividades do curso (PEC, Tutorial e Habilidades), respaldada sempre em muita teoria e pouca prática" (E8). Algo sempre complexo para se alcançar, uma vez que se está diante de um cenário heterogêneo, onde os indivíduos possuem posturas e opiniões diversas, muitas vezes conflitantes ou desarmoniosas, levando a este arranjo percebido e denunciado pelos estudantes. Logo, podem-se trazer para o debate os Parâmetros Curriculares Nacionais (BRASIL, 2002) 
que postulam entre os princípios pedagógicos que estruturam as áreas de conhecimento, a interdisciplinaridade. Lógico que não se está falando de disciplinas, mas de atividades, todavia elas exercem a mesma proporcionalidade teórica quando nos referimos a sua correlação, uma vez que estas atividades tem em seu plano de ensino o subsídio das disciplinas.

"Para observância da interdisciplinaridade é preciso entender que as disciplinas escolares resultam de recortes e seleções arbitrários, historicamente constituídos, expressões de interesses e relações de poder que ressaltam, ocultam ou negam saberes" (BRASIL, 2002, p. 88). Na perspectiva escolar, a interdisciplinaridade não tem a pretensão de criar novas disciplinas ou saberes, mas de utilizar os conhecimentos de várias disciplinas para resolver um problema ou compreender um determinado fenômeno sob diferentes pontos de vista. "A interdisciplinaridade tem uma função instrumental, trata-se de recorrer a um saber diretamente útil e utilizável para resolver às questões e aos problemas sociais contemporâneos" (p. 34).

A interdisciplinaridade acontece naturalmente se houver sensibilidade para perceber o contexto de vida e aprendizagem, mas sua prática e sistematização demandam trabalho didático de todos os professores. E, muitas vezes, por falta de tempo, interesse ou preparo, o exercício docente ignora a intervenção de outras disciplinas/saberes/atividades na realidade ou fato que está trabalhando com os alunos. Com efeito, a interdisciplinaridade se dispõe como configuração de modos de trabalhar com encontros, diálogos e conexões entre os saberes (POMBO, 2005). Assim, essa discussão no campo de formação em saúde exige um referencial mais próximo à ideia de atitude, como apresenta Fazenda (2003): atitude de buscar alternativas para conhecer mais e melhor; atitude de reciprocidade que impele à troca, ao diálogo com pares ou consigo mesmo; atitude de humildade diante da limitação do próprio saber; atitude de perplexidade ante a possibilidade de desvelar novos saberes; atitude de desafio diante do novo; atitude de responsabilidade, envolvimento e comprometimento com os projetos e as pessoas.

Foi descortinado pelos alunos que estas atitudes não acontecem, porque além das deficiências do processo de aprendizagem "existe um grande número de estudantes em sala de aula, associado à timidez destes elou a não adaptação ao método" (E29), uma vez que tiveram ao longo de toda a vida uma educação transmissiva e a participação na discussão é uma "exigência" metodológica atrelada à avaliação que é feita diante do que se expõe sobre o problema apresentado. Assim, eles referem sentir falta das aulas expositivas, da postura passiva em sala de aula, algo a tanto já acostumados. Portanto, refletem como muito árduo o processo interdisciplinar para a formação crítica, reflexiva e humanística, e a transformação do aluno para um sujeito ativo e responsável por sua própria aprendizagem (BORGES et al., 2014).

Essas características são fundamentais na metodologia ativa para que a postura e o comportamento dos discentes sejam diferenciados em sua formação e, posteriormente, como profissional. Assim, como ponto positivo apontou que "a vivência e a interação com a comunidade permitem que sejam cada vez mais disciplinados e comprometidos com a realidade social" (E14). Há um exercício profissional por parte dos alunos, o que possibilita uma experiência e preparação para atuar no mercado de trabalho e com seres humanos. Melo e Sant'ana (2012) endossam esta vivência ao apontarem a importância dos alunos em ter logo no início do curso a relação entre teoria e prática, e o contato com os pacientes e a comunidade.

Associado a esta vivência, estes acadêmicos caracterizaram a proposta de metodologias ativas adotadas na Universidade e refletiram que apesar dos mecanismos de resistência e das críticas às suas falhas de execução e estrutura, eles entendem e sabem muitas das características destes métodos - a Problematização e a Aprendizagem baseada em problemas. Todavia, convém salientar que o que foi apresentado estava muito livresco e estanque, pois caracterizaram o método diante de frases corriqueiramente referidas pelos professores, técnicos ou profissionais de saúde, como os passos da implementação da Aprendizagem baseada em problemas ou do arco de Maguerez, proposto por Bordenave e Pereira (2007).

Estas duas metodologias, para a universidade em estudo, estão sustentadas na articulação da dimensão pessoal com a profissional e a sociopolítica e se aproxima da visão crítica e reflexiva. Associada a esta noção, as Diretrizes Curriculares Nacionais (DCN) setenciaram a formação profissional pautada em "atender as necessidades sociais da saúde, com ênfase no SUS e assegurar a integralidade da atenção e a qualidade e humanização do atendimento" (BRASIL, 2001, s/p). Evidenciam a articulação das políticas dos Ministérios da Saúde e da Educação, quando ambos passaram a orientar articuladamente a formação em busca da aproximação da realidade de saúde da 
população brasileira, e na mudança do modelo de atenção e relações com a sociedade, passando a exigir a integração ensino, serviço e comunidade (GOMES et al., 2010).

Estas diretrizes foram a base para a elaboração dos projetos pedagógicos dos cursos da instituição estudada. O que afetou a estruturação do campus deste sua planta física à maneira de lidar com o conhecimento e postura em sala de aula, tendo como base teórico-conceitual os escritos de Paulo Freire $(1999,2001)$ para a metodologia da problematização, ao inferir que se configuram num referencial que fundamenta o pensamento crítico e reflexivo. Para o autor, este pensamento incide numa reflexão-ação mediada por processos educativos problematizadores, resultando em empoderamento do sujeito. O qual impulsiona um movimento de transformação, libertação e humanização, por meio do diálogo. Dessa forma, o processo de ensino traz em seu bojo estes direcionamentos, com base no referencial crítico-reflexivo, que possibilita uma práxis voltada ao ser humano.

Estes delineamentos também estão presentes nos pressupostos de John Dewey $(1998,2011)$ para a metodologia da aprendizagem baseada em problemas. O autor abordou a "cultura reflexiva" no ensino, que influenciou o pensamento pedagógico contemporâneo, dando subsídio para a "epistemologia da prática reflexiva", cuja finalidade está em formar profissionais capazes de refletir na prática, gerenciar e considerar novamente a singularidade e os conflitos de valores vivenciados no cotidiano, escapando das diretrizes da racionalidade técnica.

Assim, para que estas metodologias possam cumprir os desígnios aos quais foram propostas, é necessária maior reflexão, correlação ou aprofundamento de suas potencialidades e fragilidades pelos sujeitos envolvidos nos processo. Kleba e Wendausen (2009) afirmaram que este comportamento gera empoderamento e este se refere ao processo de mobilizações e práticas que objetivam promover e impulsionar grupos e comunidades na melhoria de suas condições de vida, aumentando sua autonomia. Assim, as pessoas podem catalisar ações ou auxiliar na criação de espaços que favoreçam e sustentem processos de mudança; renunciam ao estado de tutela, de dependência, de impotência, e transformam-se em sujeitos ativos, que lutam para si, com e para os outros por mais autonomia e autodeterminação (HERRIGER, 2006).

Por tudo que foi discutido, convém salientar que a presença do conflito é inerente às organizações e a Universidade não poderia ficar distante desta realidade, porém os sentimentos de pertencimento precisam existir para que haja o bom desempenho das pessoas por meio da concessão mútua ou promovendo a integração de modo assertivo e colaborativo. Nesse sentido, a motivação da pessoa ou do grupo assim como o objetivo final perante o conflito contribui para determinar a forma como ele será administrado (MCINTYRE, 2007).

Entendendo que o conflito resulta da diferença entre a apreciação da realidade feita pelos sujeitos em função do lugar que ocupam na organização - seus lugares na estrutura - e dependente de suas intenções - suas disposições mentais, cognitivas e afetivas, portanto denuncia o que incomoda e exigem movimentos de mudança (COSTA, 2011). Portanto, estes interesses diversos e conflitantes frente às metodologias ativas interrogam os arranjos instituídos e leva a refletir o quão urgente é entender os meios de tensão, identificar causas e atuar sobre elas, com o único objetivo de uma abordagem educacional reflexiva e humana.

\section{Considerações Finais}

Os estudantes que contribuíram para este estudo desvelaram um perceptível déficit de conhecimento frente aos princípios que regem a proposta pedagógica da instituição - Metodologias ativas - todavia, eles se apresentaram confiantes quanto às suas deficiências dentro do processo formativo, com capacidade para se autogovernarem, mas comedidos pelas normas instituídas e pouca capacidade argumentativa para ir além e contribuir de forma mais incisiva em sua graduação.

Reflete-se que talvez um dos motivos desta incongruência seja a perspectiva da formação em conflito com a visão de uma formação para a vida sem predomínio da lógica de mercado. Para que isto aconteça o empoderamento é muito importante para que ele participe da construção contínua dos seus saberes e aptidões, proporcionando-lhe meios para alcançar uma autonomia pessoal e intelectual; e, assim, adquirir uma consciência de si próprio e do mundo que o cerca.

Este empoderamento talvez possa promover a inserção dos estudantes nos projetos que se apresentem, sejam acadêmicos, sociais ou políticos, e viabilizar o engajamento, a corresponsabilização e a participação. Neste contexto, os processos interdisciplinares podem favorecer a concepção crítica e reflexiva dos sujeitos, mesmo que em seus discursos eles tenham apontado para uma 
dissociação entre as atividades do curso. A própria estrutura estabelecida do ensino por meio de atividades, que fazem uso de problemas reais ou não, para fomentar as discussões e a aprendizagem, favorece a interdisciplinaridade, pois o aluno precisa buscar em várias fontes de conhecimento para resolução dos problemas. Talvez o que esteja faltando seja sincronia entre as atividades, a ponto de deixar o aluno sem perceber as correlações e interseções existentes; e, pela necessidade de melhorarem a interação e repensar a prática diária, o ensino necessita está voltado para compreensão do mundo, onde a proposta pedagógica é refletida a todo instante não só na academia, mas com os parceiros fora dela.

O mergulho investigativo do ponto de vista prático e teórico empreendido até aqui permitiu acercar do tema, suas bases teórico-conceituais, concepções, percepções e atitudes dos sujeitos, portanto, cabe estudar os vários aspectos que os envolvem, vislumbrando seus fatores potenciais e limitantes, trazendo-os à superfície de modo a tornálos visíveis e passíveis de transformação. Afinal, acredita-se que este estudo amostral tem um valor imensurável, uma vez que pode contribuir com a própria instituição para a reflexão sobre as metodologias empregadas e as possíveis mudanças que advir.

\section{Referências}

ALBANESE, M. A.; MITCHELL, S. Problem based learning: a review of literature on its outcome and implementation issues. Acad Med., v.68, n.1, p.52-81, 1993.

ALMEIDA, E. G.; BATISTA, N.A. Desempenho Docente no Contexto PBL: Essência para Aprendizagem e Formação Médica. Revista Brasileira De Educação Médica, v.37, n.2, p.192 201, 2013.

BASTOS, C. C. Metodologias ativas. 2006.

Disponível em:

http://educacaoemedicina.blogspot.com.br/. Acesso em: 14 fev. 2017.

BERBEL, N. A. N. As metodologias ativas e a promoção da autonomia de estudantes. Semina: Ciências Sociais e Humanas, Londrina, v.32, n.1, p.25-40, 2011.
BLOOM, B. S.; HASTINGS, J. T.; MADAUS, G. F. Evaluación del aprendizaje. 1.ed. Buenos Aires: Troquel, 1975.

BORDENAVE, J. D; PEREIRA, A. A. Estratégias de ensino-aprendizagem. 28.ed. Rio de Janeiro: Ed. Vozes, 2007.

BORGES, M. C. et al. Aprendizado baseado em problemas, Brasil. Medicina, Ribeirão Preto, v.47, n.3, p.301-307, jul/set. 2014. Disponível em: http://pesquisa.bvsalud.org/portal/resource/pt/lil752836. Acesso em: 15 jul. 2016.

BRASIL. Conselho Nacional de Educação, Câmara da Educação Superior. Parecer n ${ }^{\circ} 1.33$, de 07 de agosto de 2001. Dispõe sobre as Diretrizes Curriculares da Medicina, Enfermagem e Nutrição. Brasília (DF): Ministério da Educação e Cultura, 2001.

Conselho Nacional de Saúde. Ministério da Saúde. Resolução ${ }^{\circ}$ 466/2012, de 11 de dezembro de 2012. Dispõe sobre a dignidade humana e proteção devida aos participantes das pesquisas científicas envolvendo seres humanos. Disponível em:

http://conselho.saude.gov.br/resolucoes/2012/Reso4 66.pdf. Acesso em: 14 ag. 2014.

Ministério da Educação. Secretaria de Educação. Parâmetros Curriculares Nacionais. Brasília: Ministério da Educação, 2002.

COSTA, E. de Q. Reforma curricular do curso de graduação em nutrição: a implicação dos professores no processo de mudança. $2011.147 \mathrm{f}$. [Tese]. Rio de Janeiro: UFRJ / NUTES, 2011.

CYRINO, E. G.; TORALLES-PEREIRA, M. L. Trabalhando com estratégias de ensino-aprendizado por descoberta na área da saúde: a problematização e a aprendizagem baseada em problemas. $\mathrm{Cad}$. Saúde Pública, v.20, n.3, p.780-8, 2004.

DEWEY, J. Democracia y Educación: uma introduccion a La Filosofia de La Educación. 3.ed. Madri: Ed. Morata, 1998.

. Experiência e Educação. 2.ed. (R. Gaspar, Trad.). Petrópolis, RJ: Editora Vozes, 2011.

FAZENDA, I. C. A. Interdisciplinaridade: qual o 
sentido? 1.ed. São Paulo: Paulus, 2003.

FEUERWERKER, L. Educação dos profissionais de Saúde hoje - problemas, desafios, perspectivas e as propostas do Ministério da Saúde. Revista da Abeno, v.3, n.1, p.24-27, 2003.

FREIRE, P. Pedagogia da autonomia. Saberes necessários à prática educativa. 30.ed. São Paulo: Ed. Paz e Terra, 2004.

Educação como prática da liberdade. 24.ed.Rio de Janeiro: Paz e Terra; 2001.

Educação e mudança. 23.ed. Rio de Janeiro: Paz e Terra, 1999.

FREITAS, L. C. Qualidade negociada: avaliação e contra regulação na escola pública. Educação \& Sociedade, v.26, n.92, p.1-17, 2005.

GOMES, M. P. C. et al. O uso de metodologias ativas no ensino de graduação nas ciências sociais e da saúde - avaliação dos estudantes. Ciência \& Educação, v.16, n.1, p.181-198, 2010.

HAYDT, R. C. Avaliação do Processo EnsinoAprendizagem. 5.ed. São Paulo: Ática, 1995.

HERRIGER, N. Empowerment in der sozialen Arbeit: eine Einführung. 3.ed. Stuttgart:

Kohlhammer, 2006.

KLEBA, M. E.; WENDAUSEN, E. Empoderamento: processo de fortalecimento dos sujeitos nos espaços de participação social e democratização política. Saúde Soc. São Paulo, v.18, n.4, p.733-743, 2009.

MCINTYRE, S. E.. Como as pessoas gerem o conflito nas organizações: estratégias individuais negociais. Análise Psicológica, v.XXV, n.2, p.295305, 2007.

MELO, B. C.; SANT’ANA, G. A prática da Metodologia Ativa: compreensão dos discentes enquanto autores do processo ensino-aprendizagem, Brasil. Comun. Ciênc. Saúde, v.23, n.4, p. 327-339, set/dez. 2012. Disponível em:

http://pesquisa.bvsalud.org/portal/resource/pt/lil755235. Acesso em: 25 mar. 2016.

MITRE, S. M.; et al. Metodologias ativas de ensinoaprendizagem na formação profissional em saúde: debates atuais. Ciênc Saúde Coletiva, v.13, n.(Suppl 2), p.2133-44, 2008.

PENIN, S. T. de S.; VIEIRA, S. L.. Refletindo sobre a função social da escola. In.: VIEIRA, S. L. (org.) Gestão da escola: desafios a enfrentar. Rio de Janeiro: DP\&A Editora (Biblioteca ANPAE), 2002, p. 13-45.

PERRENOUD, P. Ensinar: agir na urgência, decidir na incerteza. Trad. Cláudia Schilling. 2 ed. Porto Alegre: Artmed Editora, 2001.

POMBO, O. Interdisciplinaridade e integração dos saberes. Liinc em revista, v.1, n.1, p. 3-15, mar. 2005. Disponível em: http://revista.ibict.br/liinc/article/view/3082/2778. Acesso em: 9 dez. 2015.

QUILAN, K. M. Effects of problem-based learning curricula on faculty learning: new lenses, new questions. Adv Health Sci Educ Theory Pract., v.8, n.1, p.249-59, 2003.

RICHARDSON, R. J. et al. Pesquisa social: métodos e técnicas. 3. ed. São Paulo: Ed. Atlas, 1999.

SERAFINI, A. M. S. A autonomia do aluno no contexto da Educação a Distância. Educ. foco, Juiz de Fora, v. 17, n. 2, p. 61-82, 2012.

SILVA, R. F.; SÁ-CHAVES, I. Formação reflexiva: representações dos professores acerca do uso de portfólio reflexivo na formação de médicos e enfermeiros. Interface: Comun Saúde Educ., v.12, n.27, p.721-34, 2008.

\section{Sobre os autores}

Glebson Moura Silva: Doutor em Educação. Professor da Universidade Federal de Sergipe, Campus Lagarto.

Maria Inez Oliveira Araujo: Doutora em Educação. Professora da Universidade Federal de Sergipe, Campus 
São Cristóvão.

Shirley Verônica Melo Almeida Lima: Mestre em Saúde. Professora da Universidade Federal de Sergipe, Campus Lagarto.

Renata Ramos Menezes: Estudante de Graduação em Enfermagem da Universidade Federal de Sergipe, Campus Lagarto.

Thais Santos de Matos: Estudante de Graduação em Enfermagem da Universidade Federal de Sergipe, Campus Lagarto.

Recebido em agosto de 2017.

Aprovado em abril de 2018. 